\title{
The association between achievement goal motivation and counterproductive work behavior: the moderating effect of work engagement and the Dark Triad
}

\begin{abstract}
BACKGROUND
The objective of the article is to describe the association between counterproductive work behavior (CWB), achievement goal motivation and the moderating variables: work engagement and the Dark Triad (DT). The theoretical bases of the tested models are: the four-factor theory of achievement goal motivation (Elliot \& McGregor), the CWB conception of Spector, the JD-R model of Demerouti, the work engagement model of Schaufeli and the DT conception of Paulhus and Williams.
\end{abstract}

\section{PARTICIPANTS AND PROCEDURE}

An internet study was conducted with 138 office employees as participants. The variables were measured using the Polish versions of the following tools: achievement goal motivation - AGQ-R, counterproductive work behavior CWB-C scale, work engagement - UWES, DT - the Dirty Dozen scale.

\section{RESULTS}

The obtained results confirm the hypothesis of the differentiated strength of the additional association of the analyzed types of achievement goal motivation (mastery approach, mastery avoidance, performance approach, performance avoidance) with CWB. This link occurs in models without moderators not only for mastery avoidance. In the models with moderators, the interaction patterns are differentiated for particular types of motivation; for example, work engagement interacts only with the performance approach, while DT interacts not only with the mastery approach. Three-directional interactions increase the percentage of explained variance of the models to a small degree.

\section{CONCLUSIONS}

Moderating effects were relatively strong within the association of performance approach with CWB. Results indicate the accuracy of the theoretical bases of the studies, as well as the need for their continuation with account being taken of the types of CWB and components of DT.

\section{KEY WORDS}

counterproductive work behavior; achievement goal motivation; work engagement; Dark Triad 


\section{BACKGROUND}

Human behavior has its light and dark sides. The latter include negative behaviors in the workplace. The present work poses two general research questions: (1) Is there an association between achievement goal motivation and counterproductive work behavior (CWB)? (2) Do work engagement and the Dark Triad (DT) moderate the association between achievement goal motivation and counterproductive work behavior? In seeking answers to these questions, account has been taken of the types of achievement goal motivation proposed by Elliot and McGregor (2001), e.g. mastery approach, performance approach, mastery avoidance, performance avoidance. Statistical analyses take account of the level (high, moderate, low) of the Dark Triad, understood as a construct composed of three elements viewed as socially undesirable: psychopathy, narcissism, and Machiavellianism (Paulhus \& Williams, 2002). Analogously, three levels of work engagement, understood as the sum of its components, have been taken account of. Those are: vigor, dedication, and absorption (Schaufeli et al., 2002). The model of relations between the variables listed above and which was tested in the study is based on analysis of the theories and results of other studies that are linked with the variables: achievement goal motivation, counterproductive work behavior, Dark Triad and work engagement. A synthetic presentation of them is necessary to provide a source for arguments in favor of the tested model.

\section{GOAL ACHIEVEMENT MOTIVATION}

Henry Murray was the first (1938) in psychology to advance the hypothesis of the need for goal achievement. Later continued by McClelland et al. (1953) and Atkinson (1958), goal achievement motivation theory and its measurement have evolved, but it has kept its primary categories: success and failure. Goal achievement motivation in the contemporary globalized world retains its role in self-regulation of behavior, while the standards and conditions for achieving personal and professional goals continually change. At the same time, detrimental social phenomena continue to increase, such as exclusion and social alienation, or the negative behavior in an organization analyzed in this article. The definition of goal achievement motivation itself has evolved.

In traditional goal achievement motivation theories the primary emphasis is placed on two types of motivation: mastery goals and comparison with others (Nicholls, 1984). Mastery goals concern the skills necessary for masterful performance of a given task. The comparison with others motivation concerns demonstrating one's skills to others and drawing comparisons with them. Both motivations create specific cognitive schema and lead to different results. Over time, a distinction was made between the motivation of comparing with others with the objective of achieving a goal and of avoiding it. In this manner a trichotomous model of goal achievement motivation arose: mastery approach, performance approach (seeking the same level or better compared to others), and performance avoidance (fear of embarrassing oneself) (Elliot \& Church, 1997).

On the basis of this trichotomous model of motivation, a four-factor model of achievement goal motivation theory was created (Elliot \& McGregor, 2001). This theory introduces the division into motivations of avoidance and goal achievement into another construct - mastery goals. To put it differently, the motivations considered include mastery, performance as a path to success, and motivations aiming at avoidance resulting from the prediction of failure (Elliot \& McGregor, 2001). This produced a $2 \times 2$ matrix of four motivations: 1 - mastery approach as a path to success; 2 - mastery avoidance caused by prediction of failure and avoidance of incompetence; 3 - performance approach; 4 - performance avoidance in fear of embarrassment. The authors of the four-motivation model assume that achievement goal motivation, fear of failure, and expected skills are responsible for the individual selection of specific achievement goal motivations. Skills here mean the capability to meet the demands of the task and possessing the potential and a model for resolving that task. The dimensions of skills encompass the positive value dimension (performance approach) and the negative value dimension (performance avoidance).

Taking account of the motivations for performance and avoidance within the scope of not only the construct of comparison with others, but also of the construct of mastery, inspires us to pose the question of whether those four components of achievement goal motivation are linked with counterproductive work behavior in the same manner, or those links are different. It could be suspected that they are all positively associated. On the one hand, the affects associated with the performance approach in situations perceived as threatening to it can undergo processes of frustration, activating, for example, aggression, typical behavior for CWB. On the other hand, in people with a low level of expected achievements and failure avoidance, the fear of embarrassment may activate motivations aimed at performance avoidance, absenteeism, or property destruction, which is also a characteristic of CWB. However, people who avoid failure, motivated by fear, are afraid not only of embarrassment, but also of the consequences of revealing their negative behaviors, which may translate into stronger tendencies towards CWB compared to people striving for success. Thus, the expectation of different strength of the relationship between moti- 
vation and CWB depending on the types of motivation is based on the different mechanisms of motivation of striving and avoidance, and the difference in the effects of two types of basic motives: mastery goals and comparison with others.

There are studies whose results show an association of the mastery approach and an equitable division of goods, and the performance approach with taking more than one has contributed to a relation (Poortvliet et al., 2007). From the perspective of these results one may assume that among a given group of employees, the dominant motivation mechanisms, understood as their types in the sense proposed by Elliot and McGregor (2001), will distinguish counterproductive behavior, because in a situation of performance approach other cognitive and behavioral patterns are activated. Tasks in the workplace are usually accompanied by stress that hinders the achievement of a goal in the preferred manner and is regarded as an important predictor of CWB (Spector \& Fox, 2005; Baka, 2017). However, even if the association of each type of achievement goal motivation with CWB has the same direction, the strength should be different depending on their interactions with personality variables. This work takes two such variables into account: work engagement and the Dark Triad.

\section{COUNTERPRODUCTIVE WORK BEHAVIOR (CWB)}

In organizations, we may observe such deliberate behaviors as theft, abuse, aggression, sabotage, conflicts, absenteeism, property destruction, and hindering co-workers and superiors in performing their tasks. These financially, socially, and psychologically harmful behaviors are given different names by researchers who adhere to various theories. For example, Neuman and Baron (1998), with reference to the theory of aggression, call them "organizational aggression”; Giacalone and Greenberg (1997), based on conceptions of socialization, call them "antisocial behaviors" in an organization; Robinson and Bennett (1995) term them "deviance." In reference to the conception of social exchange, they are referred to as "organizational retaliatory behaviors" (Skarlicki \& Folger, 1997; Folger \& Skarlicki, 2005). A common contemporary term for the aforementioned behaviors is "counterproductive work behavior" (CWB; Spector \& Fox, 2005).

Several attempts at classifying counterproductive work behavior have been made. For example, Hollinger and Clark (1983) distinguished two categories referring to behavior disrupting the achievement of organizational objectives: behavior related to property deviance and that related to production deviance. Their notions were elaborated by Robinson and
Bennett (1995), who added negative interpersonal behavior towards superiors and co-workers. This article adopts the classification of CWB as suggested by Spector et al. (2006), because it provides for a division of CWB into active (abuse, theft, and sabotage) and passive (production deviance, withdrawal). The roots of active forms are in affect, and their objective is to take revenge on an organization for negative emotions experienced in it. Passive forms emerge when active forms collide with stringent sanctions from superiors and hostile behavior from co-workers. It is known that affects are a primary element in achievement goal motivation processes. This is why the classification by Spector et al. (2006) naturally leads to a broader question about the links between motivation and CWB. Additionally, Skarlicki and Folger (1997) demonstrated that in response to unfair treatment in an organization, employees can react with negative emotions, such as rage and anger, which contribute to theft and organizational sabotage. If the affects experienced at work translate into engagement in CWB, it is worth exploring how achievement goal motivation, sated with emotions, is associated with CWB. These emotions may be associated with such types of employee motivation as mastery approach, performance approach, mastery avoidance, and performance avoidance (Elliot \& McGregor, 2001). Even the classic distinction between extrinsic and intrinsic motivation implies distinct effects of those two types of motivation for responsibility for behavior, which suggests different relations between the employee and the organization; by the same token, it suggests different mechanisms involved in the emergence of behavior detrimental to the organization. If high extrinsic achievement goal motivation encounters an impediment, this may lead to a high level of CWB. And thus, the general hypothesis may be adopted that various types of achievement goal motivation will link differently with the general level of CWB as proposed by Spector et al. (2006). The various types of motivation given consideration in this project are discussed below. The predicted association between the different types of achievement goal motivation and CWB is, in light of theories of motivation and stress, so complex that it most likely depends on a range of variables that moderate it. Among its potential moderators, the most interesting one would seem to be the construct of work engagement, as it is similar, but not identical, to the construct of motivation (Derbis, 2017). Work engagement is a moderator generally valued positively, although in the absence of resources it may lead to professional burnout (Demerouti et al., 2001). Another potential moderator, usually valued negatively, is the collection of traits referred to as the Dark Triad. The justification for the moderating role played by both these constructs for the phenomenon under consideration is presented later in this article.
The association between motivation and counterproductive work behavior 


\section{WORK ENGAGEMENT}

According to Kahn (1990, p. 692), who is considered the author of the notion of engagement, it means "being fully there," that is, "emotional, cognitive, and physical fulfilment at work." According to Cohen (2007), the engaged employee is a person with a strong desire to become a member of a given organization, believes in its goals and values, and is inclined to engage in significant effort on behalf of that organization. Psychologists frequently use the construction of work engagement, combining it with job burnout (Golembiewski \& Munzenrider, 1991; Maslach et al., 2001; Maslach \& Leiter, 2008; Demerouti et al., 2001). Engagement is of a dual character (Derbis, 2017), that is, it can be conducive to job burnout if the individual does not possess the necessary resources, or can counter it if those resources are present (Demerouti et al., 2001; Leon et al., 2015).

In the present work the JD-R (Job Demands-Resources) model of burnout is employed, following the model proposed by Demerouti et al. (2001). This model is in opposition to the popular assumption adopted by Maslach and Jackson (1981) that work engagement is the polar opposite of job burnout. Demerouti et al. (2001), objecting to the depiction of the relation between work engagement and job burnout as a continuum, understand work engagement as a separate construct whose opposite is disengagement from work. Engagement thus understood expresses the attitude towards work in a given organization. It possesses three dimensions: vigor, dedication, and absorption. Vigor is a high level of energy and psychological resilience at work. Dedication entails a strong identification with one's work, enthusiasm, and pride in the performance of it. Absorption, however, is understood as concentration on work, being absorbed by it, the feeling that time goes faster when at work (Schaufeli et al., 2002). This three-dimensional understanding of work engagement is adopted in the article as the basis for operationalization of engagement in the project being reported on. It should be pointed out that work engagement here is understood as a multidimensional construct whose substantive scope partially intersects with the construct of motivation, as they share a common emotional core. Work engagement entails a relatively permanent disposition, determining one's remaining in the same workplace for a longer period of time. There are studies showing a strong negative correlation of work engagement with counterproductive work behavior (Den Hartog \& Belschak, 2012) and emotional intelligence (Brunetto et al., 2012; Bibi et al., 2013). Furthermore, work engagement reduces emotional exhaustion in more conscientious individuals who are emotionally stable (Chen et al., 2020). Therefore, it can be assumed that work engagement will be negatively related to CWB in the group of office workers analyzed in our study. This expectation is based on the assumption that low diligence and low emotional stability should eliminate these individuals from such work. Engaged, diligent and emotionally stable employees should not tend to intentionally harm an organization.

Thus, in light of those results and the aforementioned conception of engagement advanced by Schaufeli, it could be suspected that engagement in the reported studies will also be negatively associated with $\mathrm{CWB}$, and will moderate the association of CWB with achievement goal motivation. It is also suspected that achievement goal motivation, or at least some dimensions of it, may interact with engagement, and this motivation itself may interact with DT.

\section{DARK TRIAD}

The Dark Triad was incorporated into the tested model as a construct affecting the negative side of human nature, similarly to the CWB construct. Dark personality is studied based on a three-factor model (Paulhus \& Williams, 2002; O’Boyle et al., 2012), and more recently also a four-factor model (e.g. Fernández-delRío et al., 2020). Moreover, some researchers postulate one common factor "Dark Core" as an alternative to the multivariate approach (Bertl et al., 2017). Others believe that elements of the Dark Tetrad lie at the opposite pole of the Honesty-Humility dimension of the HEXACO model (Book et al., 2016; Hodson et al., 2018). So far, the DT model is more often tested in the context of other variables from the work environment than the four-factor model. The debate about the importance of configuring a dark personality model for work behavior continues. Based on literature analysis, it seems that the Dark Tetrad model and the unifactorial model do not yet have sufficient empirical and theoretical support to introduce them as a moderator in the models explaining CWB mechanisms. As Fernández-del-Río et al. (2020) write, sadism, the only component of the Dark Tetrad, absent in DT, has not yet been sufficiently studied and requires further research in the work environment. According to these authors, more rigorous testing of the Dark Tetrad's predictive relevance is needed in the context of traditional measures of normal personality. Therefore, the Dark Triad model was chosen in the present study. It is composed of psychopathy, narcissism, and Machiavellianism (Paulhus \& Williams, 2002).

Psychopathy as a construct has a clinical pedigree. Cleckley (1941) perceived the specificity of patients demonstrating a very low level of empathy, without symptoms of psychological disturbances. The traits of psychopaths lead to a differentiated tendency to take a position opposed to society in general, and this is why Paulhus and Williams (2002) treated psychopathy as a trait present on a continuum. In recent years, emphasis has been placed on the potential genetic ori- 
gins of impulsive behavior and very low level of empathy, which, however, does not exclude a role for the environment in that regard (Baron-Cohen, 2014). Associations of CWB with psychopathy have been empirically verified by, for example, Scherer et al. (2013) or Fernández-del-Río and colleagues (2020).

The mythological story of Narcissus inspired Freud (1914/2004) to describe dysfunctions consisting in directing one's drive towards oneself. Raskin and Hall (1979) count elevated perception of one's own worth, plans concerning one's greatness, improper reactions to criticism, and a deficit of empathy among elements of narcissistic personality. Studies show that narcissistic people more eagerly use social media to satisfy their need for exposure (Andreassen et al., 2017). A link between narcissism and counterproductive work behavior has been proven (Penney \& Spector, 2002).

It should be noted that CWB can also be treated as an employee's attitude towards a task. Narcissism in the above-mentioned studies of Fernández-del-Río et al. (2020) was positively associated with the task performance, while psychopathy and sadism were negative predictors. Narcissism was also a positive predictor of contextual performance, i.e. going beyond activities related to a given position, while sadism was positively associated with CWB. From the perspective of the concept of motivation presented in the current study, which includes the dimensions of performance approach and performance avoidance, these results provide the basis for incorporating the dark sides of personality into models describing negative behaviors at work. In their light, different types of motivations, especially performance approaches, may interact with DT and work engagement differently depending on their level.

The construct of Machiavellianism does not have a clinical pedigree. It was inspired by a character from a work of literature by Machiavelli (1513/2005) titled The Prince. The title character, a deceitful, cynical manipulator, became the model for the type of Machiavellianist described by Christie and Geis (1970/2013). The Machiavellianist is inclined to manipulate, take advantage of knowledge about others' weaknesses, and rejection of universal norms. It comes as no surprise that people with a low level of Machiavellianism are characterized by a rather low level of agreeableness (Jakobwitz \& Egan, 2006). In conditions of empirical induction of certain emotions, they do not change their task performance strategy (Derbis \& Wirga, 2017). Studies also prove that Machiavellians are characterized by a high level of work engagement, but they devote less attention to the high quality of social interactions in their workplace, and they do not engage in the organization (Zettler et al., 2011). Their emotional coldness, low level of trust, and inclination towards revenge create numerous interpersonal difficulties (Gurtman, 1992) that may give rise to counterproductive behavior. Fernandez-del-Rio et al. (2020) showed a positive relationship between Machiavellianism and CWB. Paulhus and Williams (2002) observed a similarity in the elements comprising psychopathy, narcissism, and Machiavellianism, and demonstrated a strong correlation among them. Jonason and McCain (2012) also consider that the Dark Triad can be treated as a single variable. Studies demonstrate that the DT is associated with the application of various techniques regarded as immoral, such as the use of manipulation, tough tactics, or the pragmatic employment of complements and kindness (Jonason et al., 2012). There are also articles indicating a link between DT and aggression, or the use of asocial strategies (Muris et al., 2017). On the basis of the meta-analysis by O'Boyle et al. (2012) decided that Machiavellianism and psychopathy are significantly negatively related to task performance. Furthermore, DT explained $28 \%$ of the deviation variance in the workplace, and all its features were positively related to CWB. Thus, it seems reasonable to expect that the DT construct treated as a whole is of fundamental importance for building CWB explanatory models.

\section{RESEARCH HYPOTHESES}

Each section of the analysis presented above contains suppositions concerning the relation between the variables analyzed in the tested model and the theoretical and empirical models that support these relations. The primary theories applied are: fourfactor achievement goal motivation theory (Elliot \& McGregor, 2001), the CWB conception as proposed by Spector et al. (Spector \& Fox, 2005; Spector et al., 2006), the JD-R model (Demerouti et al., 2001) and the associated work engagement model by Schaufeli et al. (2002), as well as the DT conception proposed by Paulhus and Williams (2002).

In the model, work engagement and DT are treated as substantively different personal resources that moderate the association of achievement goal motivation and counterproductive work behavior. The moderators themselves can also enter into an interaction that shapes CWB. For transparency of the structure of the hypotheses, the components and levels of measured variables have not been introduced; however, in statistical testing, various types of achievement goal motivations have been taken into account, such as mastery approach, performance approach, mastery avoidance, and performance avoidance, as have levels of DT and work engagement (low, moderate, high). The following hypotheses were tested:

H1. The dominant types of achievement goal motivation among employees will be positive, but of various strength, and will be associated with counterproductive behavior.

$\mathrm{H} 2$. Work engagement is negatively associated with $\mathrm{CWB}$.
The association between motivation and counterproductive work behavior 
H3. DT is positively associated with CWB.

H4. The association between achievement goal motivation and CWB depends on the interaction of types of achievement goal motivation with the variables work engagement and the Dark Triad. Engagement to work and DT intensifies CWB in interaction with the success orientation and weakens in interaction with failure avoidance.

Romuald Derbis

\section{PARTICIPANTS}

Anonymous studies were performed in the spring of 2018 among white-collar employees in southwestern Poland. The selection of the study sample $(N=138$, women $=31$, men $=107 ;$ average age $M=39.60$ years, $S D=3.10$; average time in work $M=9$ years) is justified by the specificity of this form of work, consisting in the necessity of frequently entering into work-related interpersonal contacts, exchanging information, and a strong dependence on hierarchy in the organization. It was assumed that this type of work will facilitate achievement goal motivation and work engagement. Participants were recruited via industry groups on Facebook and webpages with industry-related forums. All participants expressed informed consent to participate in the study.

\section{MEASUREMENT}

Achievement goal motivation. Achievement goal motivation was measured using the Polish adaptation (Lipowska, 2016) of the Achievement Goal Questionnaire Revised (AGQ-R; Elliot \& Murayama, 2008). It contains 12 statements comprising 4 scales with responses scored between 1 (doesn't describe me at all) and 7 (describes me perfectly). The survey is based on the assumption of the presence of the four types of motivation described above (Elliot \& McGregor, 2001; Elliot \& Murayama, 2008). Its four scales, linked to the four types of motivation, achieved high reliability in the reported studies (mastery approach $\alpha=.91$; performance approach $\alpha=.95$; mastery avoidance $\alpha=.87$; task avoidance $\alpha=.94$ ).

Counterproductive work behavior. The measure of counterproductive work behavior was done using the Counterproductive Work Behavior - Checklist (CWB-C; Spector et al., 2006), in its Polish version (Baka et al., 2015). It is composed of 32 statements, responses from 1 (never) to 5 (every day). The statements comprise four factors of satisfactory reliability in the studies. The Cronbach's $\alpha$ coefficients are for the total result $\alpha=.92$, sabotage $\alpha=.74$, abuse $\alpha=.94$, theft $\alpha=.54$, withdrawal $\alpha=.78$.
Work engagement. Work engagement was examined using the Utrecht Work Engagement Scale (UWES; Schaufeli \& Bakker, 2003). Its Polish adaptation was prepared by Szabowska-Walaszczyk et al. (2011). The UWES is based on the concept of work engagement proposed by Schaufeli et al. (2002) and Schaufeli and Salanova (2007). The scope of responses for the 12 statements, 4 for each scale, is from 0 (never) to 6 (always/every day). Engagement level is indicated by the total points from all responses. In the reported studies, all three scales comprising the UWES achieved satisfactory Cronbach's $\alpha$ reliability coefficients for vigor (.77), absorption (.86), and dedication (.86), with a total score of .93 .

Dark Triad. Measurement of the Dark Triad was done using the Polish adaptation of the Dirty Dozen scale (Jonason \& Webster, 2010; Polish adaptation by Czarna et al., 2016), whose aim is to measure psychopathy, narcissism, and Machiavellianism; the sum of responses provides the Dark Triad coefficient. It contains 12 positions, 4 for each component of the DT. The scope of responses runs from 1 (not at all true) to 5 (absolutely true). In the main study, satisfactory reliability coefficients were recorded. DT total, $\alpha=.88$, Machiavellianism, $\alpha=.86$, psychopathy, $\alpha=.75$, narcissism, $\alpha=.81$.

\section{DATA ANALYSIS STRATEGY}

To test the hypotheses, moderated moderation analysis was conducted using the PROCESS macro, version v3.2. 5000 bootstrapping simulations were used in testing models number 3 and 1 (Hayes, 2009). The scheme of the analyzed model is presented in Figure 1. Four models were tested. In each of them analysis was done of the association of one of the four motivation types with counterproductive work behavior, moderated by the Dark Triad and engagement.

In the statistical sense, this means that the following were tested as predictors of counterproductive work behavior: one of the dimensions of motivation, the Dark Triad, engagement, and four interactions of those variables (e.g., for the mastery dimension: Dark Triad*engagement; Dark Triad $^{*}$ mastery; mastery ${ }^{*}$ engagement; mastery ${ }^{*}$ Dark Triad*engagement). For each type of motivation, we also tested the significance for CWB of the interaction between DT and work engagement, as well as threeway interactions (e.g., mastery* ${ }^{*} T^{*}$ engagement).

\section{RESULTS}

The results will be presented in four steps, aligned with the four tested models. Each model is linked with one type of achievement goal motivation proposed by Elliot and McGregor (2001) and Elliot and 


\section{Figure 1}

Conceptual model of the relationship between motivation and counterproductive work behaviors, motivated by work engagement and the Dark Triad

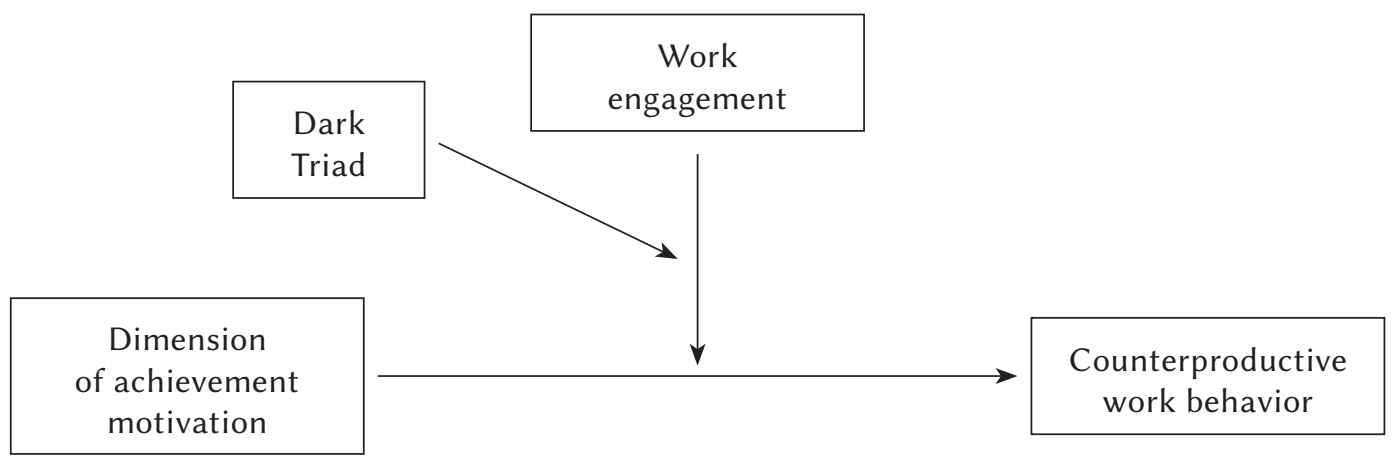

The association between motivation and counterproductive work behavior
Murayama (2008). In the next section, summary and discussion, the achieved results are applied to the hypotheses posed above.

\section{MODEL 1 (M1) - MASTERY APPROACH}

Analysis of Model 1, which concerns the association between mastery approach and CWB, moderated by the Dark Triad and engagement, exhibited several dependencies. First, mastery approach was positively and moderately associated with counterproductive work behavior $(r=.41, p<.001)$. Analysis of this association accounting for moderators demonstrated that counterproductive work behavior is explained in a statistically significant manner only through engagement in work, which buffers CWB (Figure 2).

None of the analyzed moderating effects was statistically significant. Generally, the model explained $71 \%$ of the variance of counterproductive work behavior; $F(7,134)=46.82, p<.001, R^{2}=.71$. However, inclusion of moderators in the analysis did not expand the scope of the explanation for counterproductive work behavior in a statistically significant manner $\left(R^{2}=\mathrm{ns}\right)$.

\section{MODEL 2 (M2) - PERFORMANCE APPROACH}

In the case of the model in which analysis was done on the association between performance approach

\section{Figure 2}

Model of relationship (non-standardized $\beta$ ) between mastery approach and counterproductive work behavior, moderated by work engagement and the Dark Triad

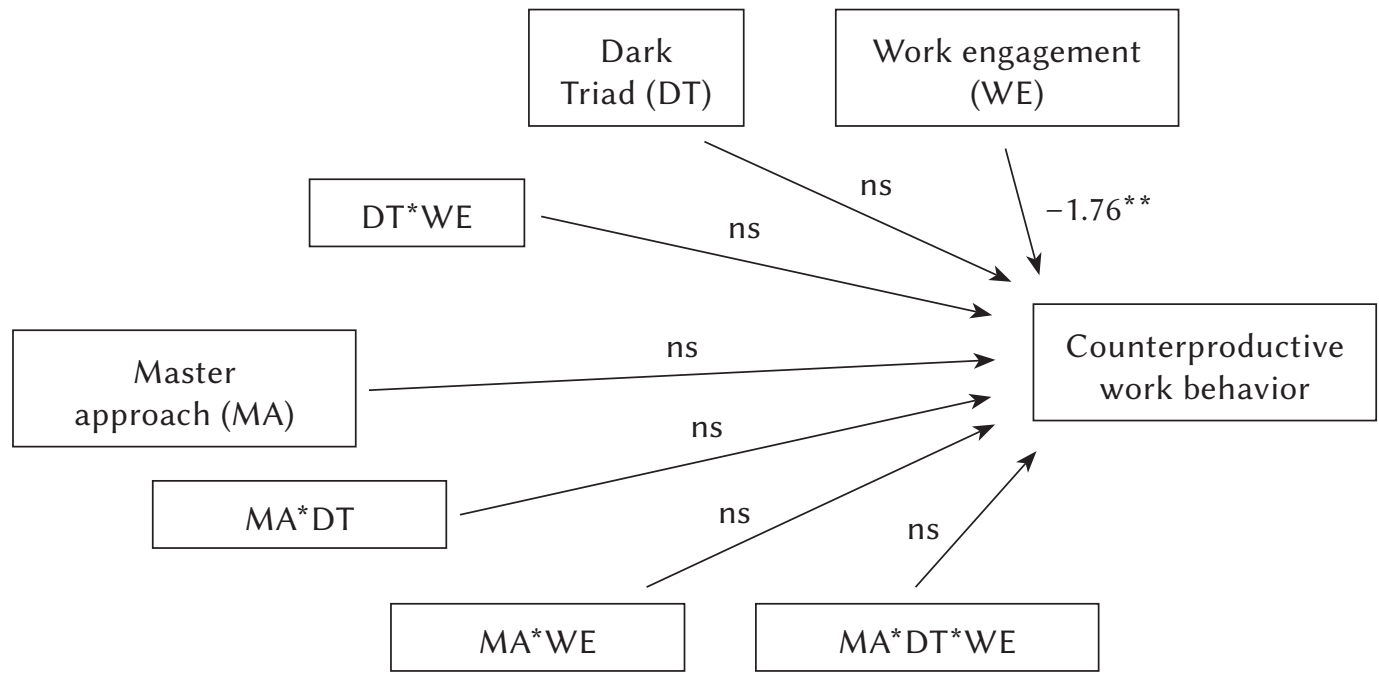

Note. ${ }^{*} p<.05,{ }^{* *} p<.01,{ }^{* * *} p<.001 ;$ ns - statistically non-significant result. 
as a dimension of motivation with counterproductive work behavior, the results demonstrated stronger main and moderating effects than in the case of mastery approach as a predictor of counterproductive work behavior. First, the correlation between performance approach and counterproductive work behavior was positive but weak $(r=.24, p<.05)$. Second, in the model with moderators, all of the analyzed interactions and moderators offered a statistically significant explanation for counterproduc- tive work behavior. Generally, this model explained $71 \%$ of the variance of counterproductive behavior, $F(7,132)=46.54, p<.001, R^{2}=.71$. Introducing a three-directional interaction to the model indicated that $2 \%$ of the variance is linked with the interaction of moderators, $R^{2}=.02, p<.05$. The results concerning the interaction effect of moderators on the association between performance approach and counterproductive work behavior are summarized in Table 1 and Figures 3 and 4.

\section{Figure 3}

Model of relationship (non-standardized $\beta$ ) between performance approach and counterproductive work behavior, moderated by work engagement and the Dark Triad

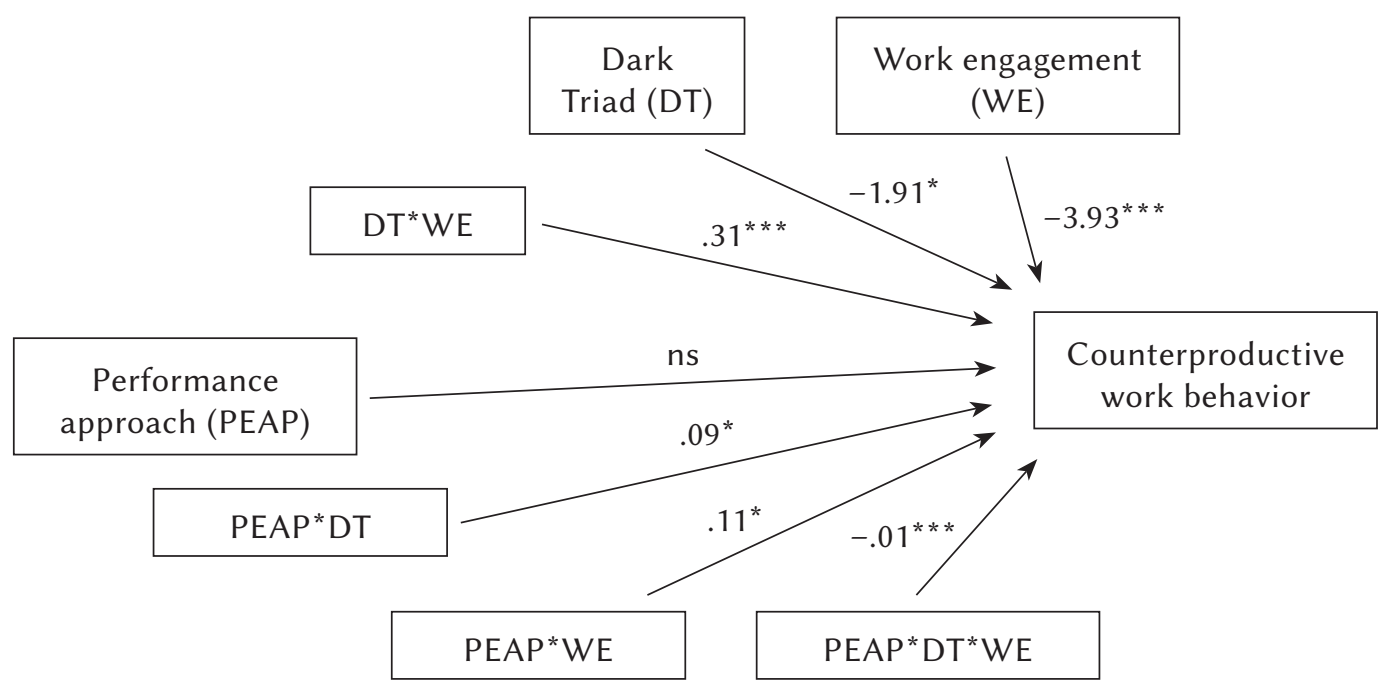

Note. ${ }^{*} p<.05,{ }^{* *} p<.01,{ }^{* * *} p<.001 ; \mathrm{ns}-$ statistically non-significant result.

Table 1

Relationship (non-standardized $\beta$ ) between performance approach and counterproductive work behavior, moderated by work engagement and the Dark Triad

\begin{tabular}{ccc}
\hline \multicolumn{2}{c}{ Category of moderator level } & $\begin{array}{c}\text { Relationship between performance approach and counterpro- } \\
\text { ductive work behavior (non-standardized } \beta \text { and LLCI-ULCI) }\end{array}$ \\
\hline Engagement & Dark Triad & $\mathrm{ns}[-.111 ; .012]$ \\
low & low & $.26^{* *}[.135 ; .384]$ \\
low & moderate & $.38^{* *}[.164 ; .597]$ \\
moderate & high & $.27^{* * *}[.060 ; .267]$ \\
low & moderate & $.29^{* * *}[.089 ; .491]$ \\
moderate & high & $.30^{* *}[.137 ; .464]$ \\
high & low & $.43^{* *}[.180 ; .681]$ \\
high & moderate & $.31^{*}[.136 ; .484]$ \\
high & high & $.20^{*}[.070 ; .331]$ \\
\hline
\end{tabular}

Note. ${ }^{*} p<.05,{ }^{* *} p<.01,{ }^{* * *} p<.001 ;$ ns - statistically non-significant. 
The results in Figure 3 indicate that all of the analyzed predictors of counterproductive work behavior, apart from performance approach, provide a statistically significant explanation of their variance. The data presented in Table 1 and Figure 4 are helpful in interpreting the results of the interaction of moderators with performance approach.

The data in Table 1 indicate that the strength of the association between performance approach and counterproductive work behavior is the strongest in the group of participants with a moderate level of en-

Figure 4

Strength of relationship between performance approach and counterproductive behavior depending on the category of the Dark Triad level (see Table 1 for all $\beta$ values)

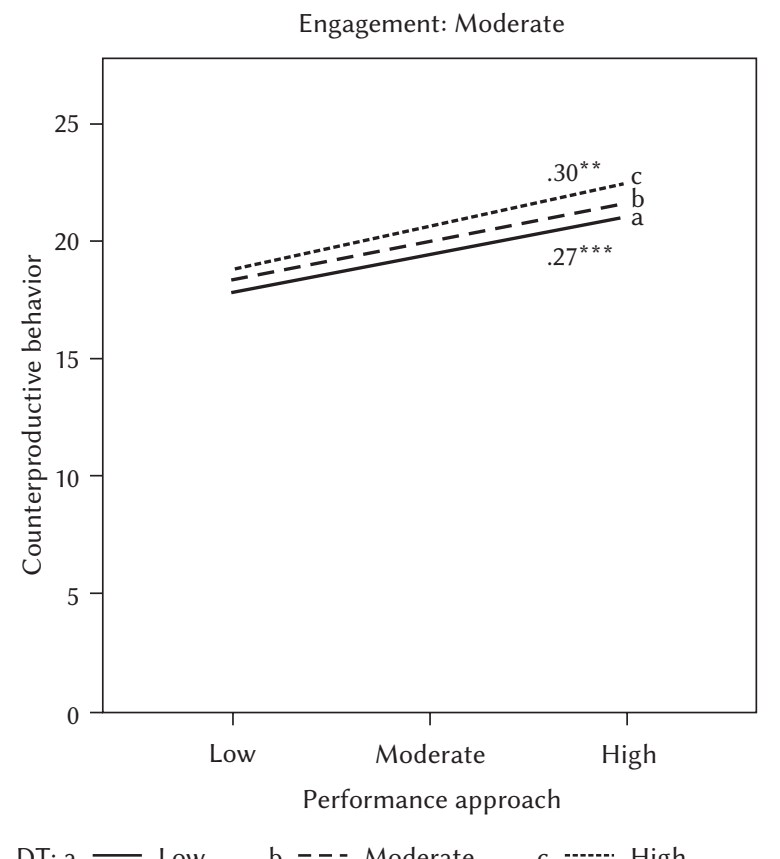

gagement. However, the results in this group appear rather homogeneous, irrespective of the level of Dark Triad. The pattern of results is different in groups of high and low engagement, where the differentiation of strength is greater. These relations are more clearly visible in Figure 4.

In the group with low engagement and low level of Dark Triad, the association between performance approach and counterproductive work behavior is not statistically significant, whereas in the group with a high level of both moderators, it is relatively weak.
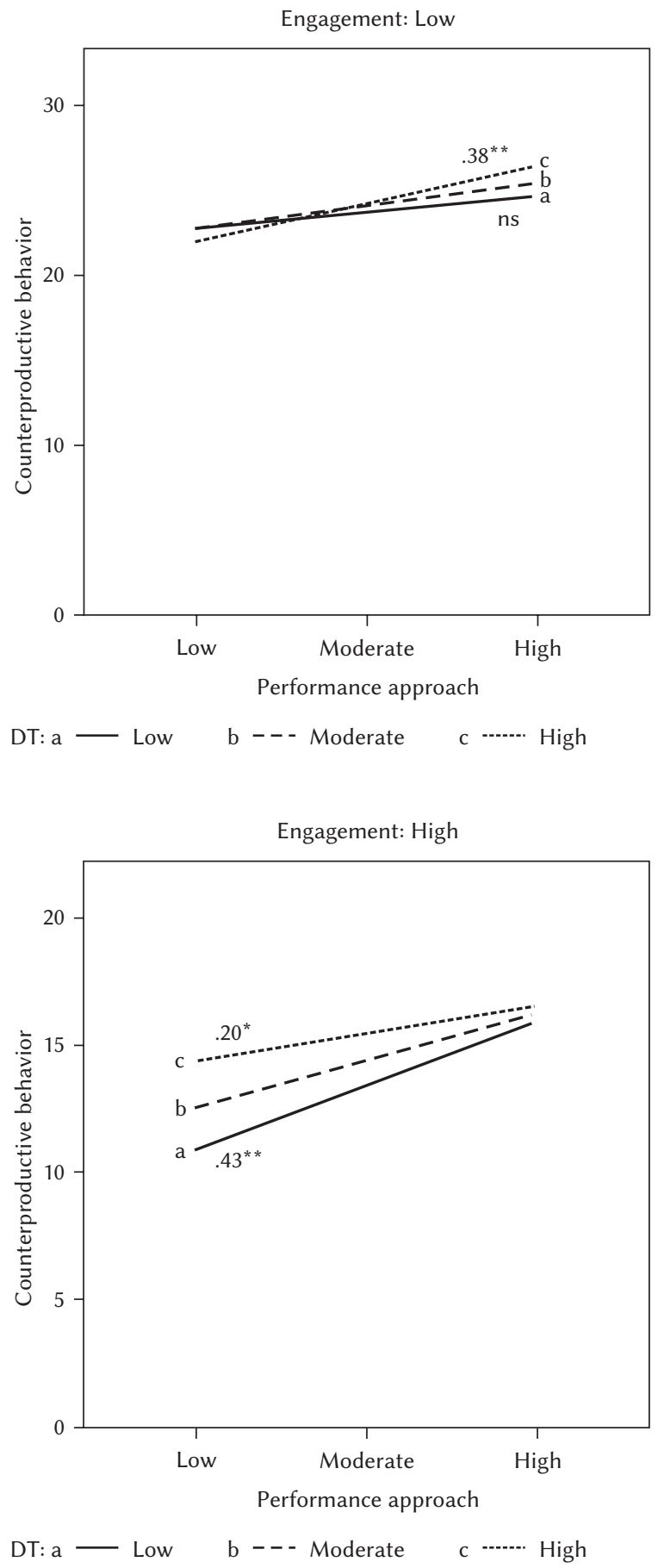

The association between motivation and counterproductive work behavior 


\section{MODEL 3 (M3) - MASTERY AVOIDANCE}

The next model tested in the study concerned the significance of mastery avoidance for CWB. The association between mastery avoidance and counterproductive work behavior without accounting for moderators was not statistically significant $(r=.06$, $\mathrm{ns})$. The model explained around $70 \%$ of the variance of the dependent variable; $F(7,133)=44.34, p<.001$, $R^{2}=.70$. Introducing three-directional interaction cant explanation for the variance of counterproductive work behavior.

As can be seen in Figure 5, the only statistically significant interaction was the relation between the Dark Triad and mastery avoidance.

The results shown in Table 2 indicate that a low and moderate level of Dark Triad is associated with greater strength of the association between mastery avoidance and counterproductive work behavior, but this relation did not apply to people with a low level of engagement. This interaction is depicted in Figure 6.

Figure 5

Model of relationship (non-standardized $\beta$ ) between mastery avoidance and counterproductive work behavior, moderated by work engagement and the Dark Triad

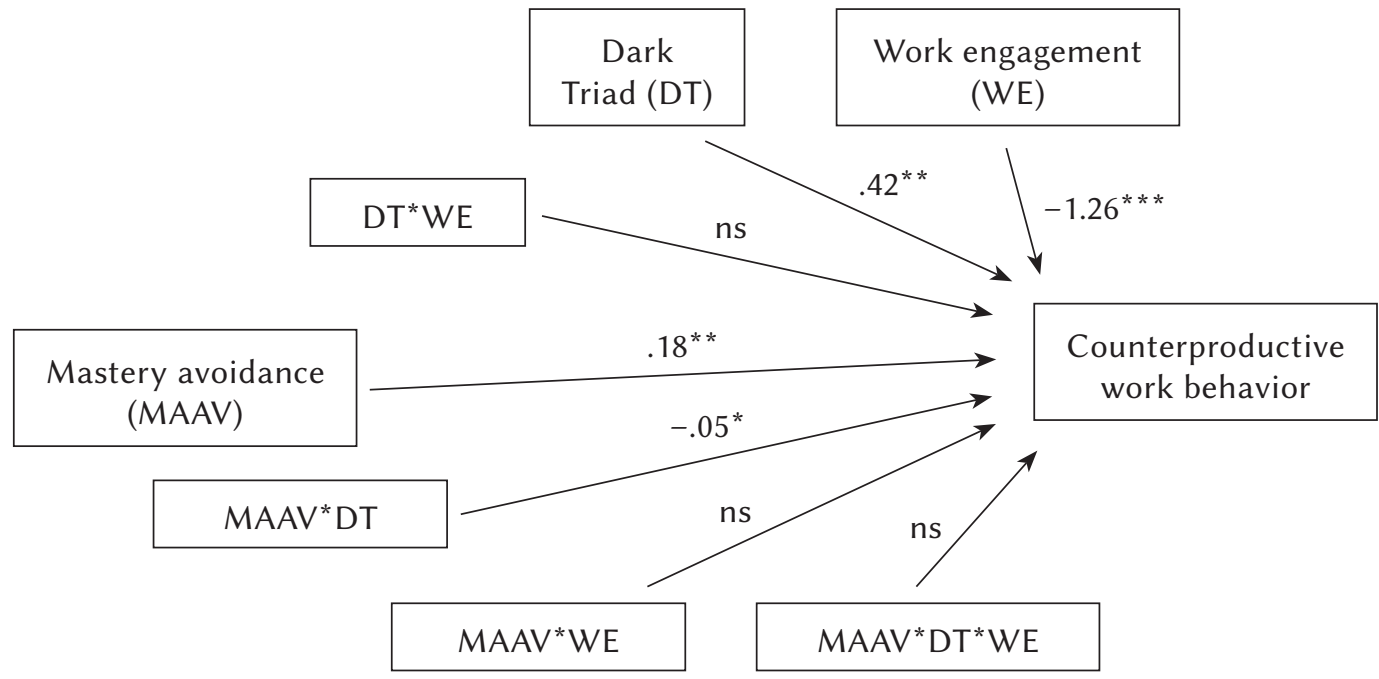

Note. ${ }^{*} p<.05,{ }^{* *} p<.01,{ }^{* * *} p<.001, \mathrm{~ns}-$ statistically non-significant result.

Table 2

Relationship (non-standardized $\beta$ ) between mastery avoidance and counterproductive work behavior, moderated by work engagement and the Dark Triad

\begin{tabular}{|c|c|c|}
\hline \multicolumn{2}{|c|}{ Category of moderator level } & \multirow{2}{*}{$\begin{array}{l}\text { Relationship between mastery avoidance and counterproductive } \\
\qquad \text { work behavior (non-standardized } \beta \text { ) }\end{array}$} \\
\hline Engagement & Dark Triad & \\
\hline low & low & ns $[-.021 ; .123]$ \\
\hline low & moderate & ns $[-.002 ; .248]$ \\
\hline low & high & ns $[-.131 ; .089]$ \\
\hline moderate & low & $.30^{* * *}[.178 ; .454]$ \\
\hline moderate & moderate & $.18^{* *}[.068 ; .292]$ \\
\hline moderate & high & ns $[-.007 ; .126]$ \\
\hline high & low & $.52^{* *}[.309 ; .731]$ \\
\hline high & moderate & $.31^{*}[.121 ; .400]$ \\
\hline high & high & ns $[-.009 ; .160]$ \\
\hline
\end{tabular}

Note. ${ }^{*} p<.05,{ }^{* *} p<.01,{ }^{* * *} p<.001$, ns - statistically non-significant. 


\section{MODEL 4 (M4) - PERFORMANCE AVOIDANCE}

The last analyzed model is the association between performance avoidance and counterproductive work behavior moderated by the Dark Triad and engagement. The correlation between performance avoidance and counterproductive work behavior without inclusion of moderators was positive and weak $(r=.18, p<.05)$. The model explains $71 \%$ of the variance of the explanatory variable; $F(7,133)=46.69$, $p<.001, R^{2}=.71$. The three-directional interaction was not statistically significant in this model.

Analysis of the interaction effects depicted in Figure 7 showed that the only significant effect, similarly to the earlier M3 model, is the interaction of the Dark Triad with avoidance; in this case, performance avoidance, and thus failure. The results are presented in Table 3 and depicted in Figure 8.

They show that low and moderate levels of Dark Triad are associated with a stronger link between failure avoidance and counterproductive work behavior than in the case of a low level of the Dark Triad.

\section{CONCLUSIONS AND DISCUSSION}

The models will be described in the summary from the perspective of their contribution to verification of the hypotheses.

Thus, H1, concerning the differentiated strength of the positive association of particular types of achievement goal motivation with CWB, was partially confirmed. In the analyses conducted without moderators, all types of motivation except for mastery avoidance are positively but moderately or weakly linked with CWB. Particularly conducive to counterproductive work behavior is mastery approach, which concerns the competences necessary for performance mastery of a given task, and not demonstrating one's compe-

\section{Figure 6}

The strength of the relationship between mastery avoidance and counterproductive behavior depending on the category of the Dark Triad level

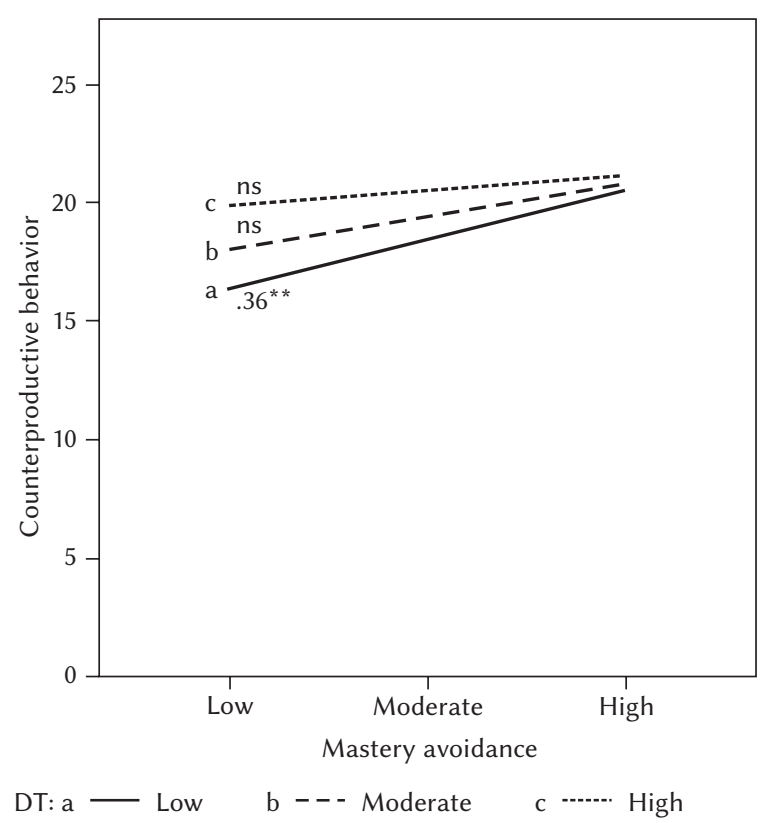

The association between motivation and counterproductive work behavior

Figure 7

Model of relationship (non-standardized $\beta$ ) between performance avoidance and counterproductive work behavior, moderated by work engagement and the Dark Triad

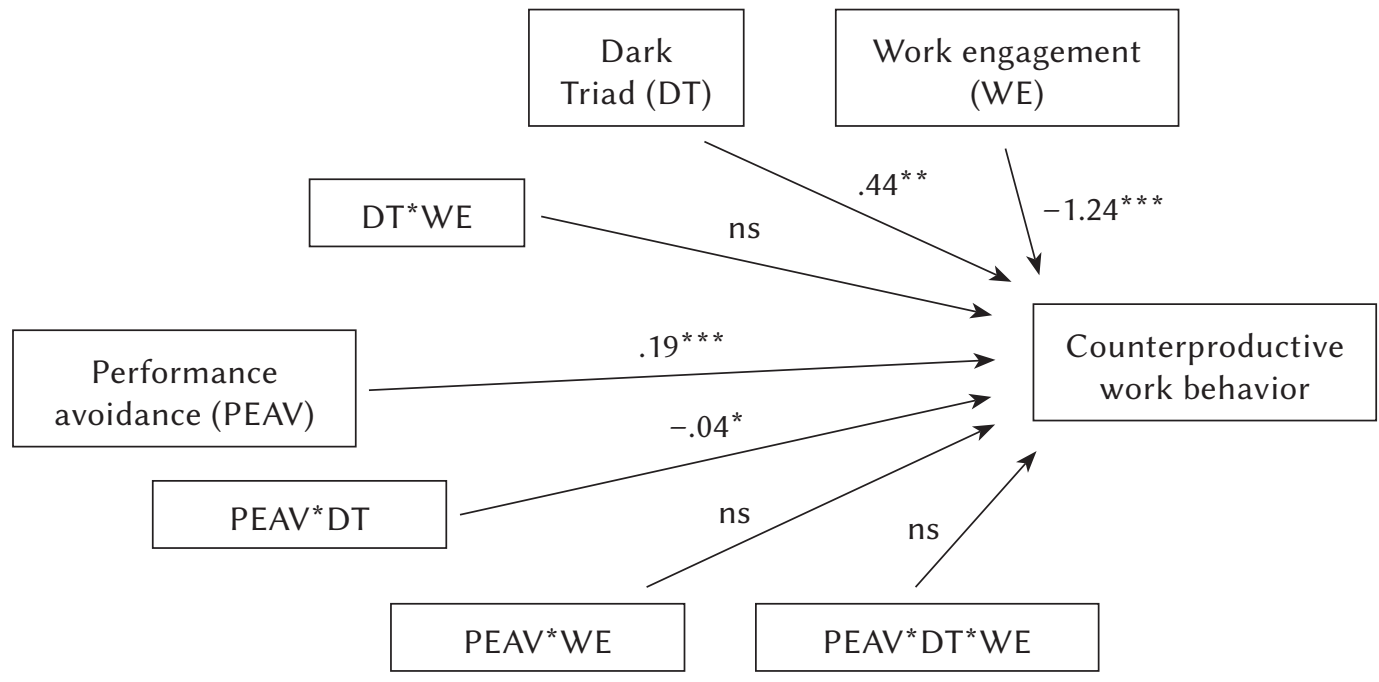

Note. ${ }^{*} p<.05,{ }^{* *} p<.01,{ }^{* * *} p<.001 ;$ ns - statistically non-significant result. 
Table 3

Relationship (non-standardized $\beta$ ) between performance avoidance and counterproductive work behavior, moderated by work engagement and the Dark Triad

\begin{tabular}{|c|c|c|}
\hline \multicolumn{2}{|c|}{ Category of moderator level } & \multirow{2}{*}{$\begin{array}{c}\text { Relationship between performance avoidance } \\
\text { and counterproductive work behavior (non-standardized } \beta)\end{array}$} \\
\hline Engagement & Dark Triad & \\
\hline low & low & $.18^{*}[.010 ; .178]$ \\
\hline low & moderate & $.13^{*}[.061 ; .198]$ \\
\hline low & high & ns $[-.002 ; .105]$ \\
\hline moderate & low & $.28^{* * *}[.062 ; .481]$ \\
\hline moderate & moderate & $.19^{* *}[.056 ; .324]$ \\
\hline moderate & high & ns $[-.118 ; .287]$ \\
\hline high & low & $.42^{* *}[.307 ; .534]$ \\
\hline high & moderate & $.26^{*}[.104 ; .416]$ \\
\hline high & high & ns $[-.049 ; .234]$ \\
\hline
\end{tabular}

Note. ${ }^{*} p<.05,{ }^{* *} p<.01,{ }^{* * *} p<.001 ;$ ns - statistically non-significant.

\section{Figure 8}

Strength of the relationship between performance avoidance and counterproductive behavior depending on the category of the Dark Triad level

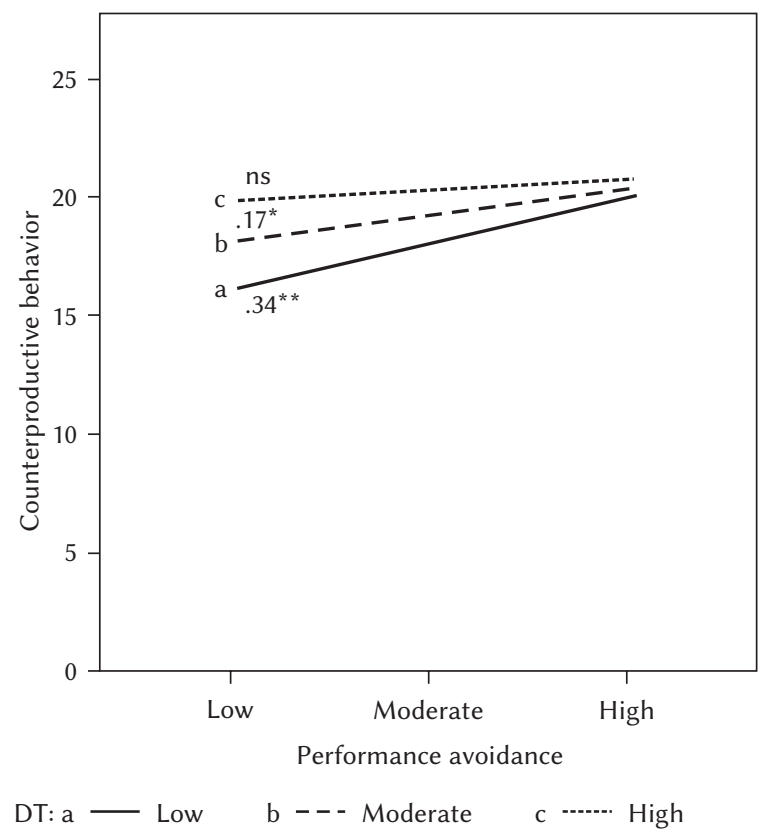

tences to others, as is the case with motivation based on comparisons with others, that is, the performance approach or performance avoidance. In the models with moderators of CWB, a statistically significant positive link was demonstrated only with avoidance motivations, that is, mastery avoidance and performance avoidance. The recorded results thus show that achievement goal motivation tends to enhance counterproductive work behavior, particularly when based on avoidance motivations. This means that from the perspective proposed by Elliot and Church (1997) and Elliot and McGregor (2001), of greater significance for activating CWB is performance avoidance out of fear of embarrassment and failure than mastery approach or performance approach at the same or higher level than others. However, these dependencies become more complicated if we simultaneously take into consideration the moderating role of work engagement and the Dark Triad. H4 addresses this issue, as will be discussed below.

As for verification of $\mathrm{H} 2$, the most distinct pattern is that confirming the predicted negative relation of work engagement with CWB, statistically significant in analyses of all four tested models with moderators. Engagement, understood holistically as the general effect of vigor, absorption, and dedication, weakens CWB. H2 can be considered as confirmed. By the same token, predictions based on the engagement model of Schaufeli et al. (2002) were confirmed, as well as the results of studies conducted by Den Hartog and Belschak (2012).

Regarding verification of $\mathrm{H} 3$ the positive association of the Dark Triad and CWB was consistent with predictions only in the interactive models concerning mastery avoidance and performance avoidance. DT exhibited a positive association with CWB in the model for mastery avoidance and performance avoidance, negative in the model for performance approach, while there was no link in the mastery approach model. H3 can be only partially supported. This partial confirmation may indicate a dependence of the association between CWB and DT on the level 
of work engagement and level of DT, or the level of its components, which were not analyzed separately in the reported studies. For example, narcissistic individuals do not readily engage in counterproductive work behavior when such behavior hinders them in achieving performance mastery, of great importance for their positive image in the eyes of others and of themselves. A detailed analysis accounting for the associations of DT components with types of CWB is the objective of future studies.

$\mathrm{H} 4$ is of particular importance for the reported study, because it takes into account interactions of the tested variables. As it turns out, the patterns of these interactions are different for particular types of motivation. And thus, from among the four tested models of associations between motivation and CWB, work engagement moderates only one: the association of CWB with performance approach, reinforcing CWB. Engagement as an individual predictor is negatively associated with CWB, but in interaction with performance approach as an achievement goal motivation type, its effect changes and it reinforces CWB.

This result could be explained using the conception developed by Elliot and McGregor (2001), according to which the performance approach is the drive to accomplish a task to the same level as or better than others. Its essence consists in demonstrating competencies to other people and comparing oneself with them in the dimension of the drive to accomplish a task. Perhaps the path to achieving this goal is the manifestation of aggressive behavior towards others, sabotage, or abuse; the hypothesis requires further exploration.

It should be observed that the association between performance approach and CWB, in the results of the conducted analyses, is distinguished by the statistical significance of moderating effects. In this model (M2), the interaction both of work engagement and of DT with performance approach enhances CWB (Figure 3). It would thus seem that these interactions are a relatively strong regulator of counterproductive work behavior. In this model, the interaction of DT with work engagement is statistically significant (enhances CWB), as is the three-directional interaction of task ${ }^{*} \mathrm{DT}^{*}$ engagement (weakens CWB).

As for the moderating effects of DT, with the exception of mastery approach, DT is a weak moderator of the association of all types of motivation with CWB. However, in the case of mastery avoidance and performance voidance, their negative impact on CWB is weakened, not reinforced, as in the case of performance approach. As we should expect, the moderating role of work engagement and DT in shaping CWB is different in the motivational mechanisms of drive and the motivational mechanisms of avoidance. If employees adopt a goal-based orientation as a path to success, then work engagement and DT reinforce CWB. Psychopaths, Machiavellians, and narcissistic people will, as appropriate to their means of goal achievement and objectives, also strive to achieve them through counterproductive work behavior. If they predict a failure, both moderators weaken it. In this situation, fear of embarrassment and failure is dominant, and those fears can slightly restrict activity, including CWB. When we also take into account that the three-directional interaction (motivation type* $\mathrm{DT}^{*}$ engagement) is of little significance $(2 \%)$ for CWB variance only in respect of performance approach, we can then say that this type of motivation is the most sensitive to interaction with the tested moderators.

Of course, this discussion must also take account of levels of work engagement and DT. As concerns the motivation of goal achievement, here as well there are interesting dependencies regarding the motivation of performance approach, which is the only one that interacts with both moderators. Work engagement is generally negatively linked with CWB in each of the four models with interaction, but in model M1 this association resembles an inverted U. Regardless of DT level, it is the strongest at a moderate level of engagement; however, a high level of both moderators weakens this link, and at a low level the association is not statistically significant. However, it is at its strongest when DT is low and work engagement is high, and when CWB is at its lowest level. As for the mastery avoidance motivation, this dependence does not affect people with a low level of engagement. This means that in M3, the emergence of CWB requires work engagement. In light of Schaufeli's conception of engagement (Schaufeli et al., 2002) and the JD-R model (Demerouti et al., 2001), people who are not engaged in work and who avoid mastery seem to have relatively few reasons for engaging in CWB. In the case of performance avoidance (M4), things are slightly different. Regardless of engagement level, low and moderate DT is associated with a greater strength of its link with counterproductive work behavior than high DT, when it is not statistically significant. In the light of studies on people with high DT (Paulhus \& Williams, 2002; Zettler et al., 2011; Baron-Cohen, 2014), it turns out that they may have a high, primarily Machiavellian, level of work engagement, but not of engagement in the organization or social interactions. If they are simultaneously motivated by performance avoidance, that is, they fear the embarrassment of appearing worse than others, they will also avoid CWB, which may favor such embarrassment.

\section{MAJOR FINDINGS AND PRACTICAL IMPLICATIONS}

The primary results of the reported study can have practical application. Differences have been demonstrated in tendencies to exhibit CWB depending on
The association between motivation and counterproductive work behavior 
a given employee's dominant achievement goal motivation category, and its interaction with levels of engagement and of Dark Triad. Taking the perspective of psychological practice the results thus indicate the necessity of programs to counteract CWB accounting for not only levels of stress at work, which is frequently treated as the primary cause of such behavior (Skarlicki \& Folger, 1997; Spector et al., 2006), but also for the type of achievement goal motivation, level of engagement, and level of DT. It should be kept in mind that while work engagement is generally negatively associated with CWB in the interaction models, in interaction with DT, negative behavior increases exceptionally for performance approach. Additionally, for this motivation, based on comparisons with others, the strongest associations of DT with work engagement emerge at a moderate level. In turn, for motivation oriented on the possession of competences, such as mastery avoidance, the links between DT and work engagement are also relatively strong for the moderate level of the latter variable. However, when the level of both moderators is strong, there is no such interaction.

Suggestions for CWB prevention practices must therefore be cautious and different regarding successoriented individuals, as well as failure avoiding individuals. First of all, in developing CWB prevention programs it should be helpful to identify the level of all independent variables analyzed in the present study. It would be recommended to assess the type of motivation the employee is guided by, as well as the level of his engagement and DT. In the case that the employee is success oriented, stimulation of his success can be unfavorable, because he intensifies CWB, especially in interaction with the moderate levels of work engagement and DT. If the employee is characterized by failure avoidance and high DT level, then in the light of our findings, it may turn out that their interaction serves the organization, because it weakens CWB. This means that the presence of "bad boys" in the organization may be favorable, which is also suggested by Fernández-del-Río et al. (2020). Thus, in developing the aforementioned programs, it should be helpful to identify the level of all independent variables analyzed in the present study.

\section{LIMITATIONS AND SUGGESTIONS FOR FUTURE RESEARCH}

Measurement of work engagement is based on the CWB-C total index. Therefore, the relatively low reliability of the theft subscales is not as meaningful as when each of them would be analyzed separately. However, the reliability of a scale slightly below the standards is a limitation regarding the validity of our findings. The relatively small sample size in the present study is another limitation. Currently actions are being undertaken to improve the reliability of the theft scale. Furthermore, research is planned involving a large number of employees from various professions.

The internal and external accuracy of the recorded results would certainly be improved by conducting separate analyses for the components of work engagement; there are plans for such analyses, but they require further studies on a greater sample of individuals taken from a diverse group of professions. The same is true for the components of DT. In accordance with the assumptions underlying DT, this construct concerns the joint treatment of psychopathy, Machiavellianism, and narcissism owing to their shared traits (Paulhus \& Williams, 2002; Jonason \& McCain, 2012; Jonason et al., 2012). Separate treatment of the components of DT would thus be a de facto abandonment of the empirical application of that construct.

In continuing and replicating these studies, it would be advisable to enrich the tested models with mediators of the relation between achievement goal motivation and CWB, accounting also for models of moderated mediation. Potential mediators for this relation may be personal resources such as work satisfaction, work-home balance, or the complex and interesting but less popular construct of Core SelfEvaluations (Judge et al., 1997), frequently used for studying behaviors in an organization (Judge et al., 2005; Judge, 2009). Apart from socio-demographic variables, moderators of this mediation may be organizational resources, such as perception of support from co-workers and superiors, buffering the positive relation of the Dark Triad and its interactions with CWB present in the reported studies.

In the light of the results obtained e.g. by Fernández-del-Río et al. (2020), sadism was the most important predictor of $\mathrm{CWB}$ in them compared to other dark personality traits, including psychopathy. Therefore the Dark Tetrad model should also be tested in CWB studies.

\section{REFERENCES}

Andreassen, C. S., Pallesen, S., \& Griffiths, M. D. (2017). The relationship between addictive use of social media, narcissism, and self-esteem: Findings from a large national survey. Addictive Behaviors, 64, 287293. https://doi.org/10.1016/j.addbeh.2016.03.006

Atkinson, J. (1958). Towards experimental analysis of human motivation in terms of motives, expectancies and incentives. In J. Atkinson (Ed.), Motives in fantasy, action and society (pp. 288-305). Van Nostrand.

Baka, Ł. (2017). Zachowania kontrproduktywne w pracy. Dlaczego pracownicy szkodza organizacji? [Counterproductive work behaviours. Why employees are damaging the organization?]. Scholar. 
Baka, Ł., Derbis, R., \& Walczak, R. (2015). Psychometryczne właściwości Kwestionariusza Zachowań Kontrproduktywnych CWB-C [Psychometric properties of the Polish version of Counterproductive Work Behavior - Checklist (CWB-C)]. Czasopismo Psychologiczne, 21, 163-174.

Baron-Cohen, S. (2014). Teoria zła. O empatii i genezie okrucieństwa [The science of evil: On empathy and the origins of cruelty]. Smak Słowa.

Bertl, B., Pietschnig, J., Tran, U. S., Stieger, S., \& Voracek, M. (2017). More or less than the sum of its parts? Mapping the Dark Triad of personality onto a single Dark Core. Personality and Individual Differences, 114, 140-144. https://doi.org/10.1016/ j.paid. 2017.04.002

Bibi, Z., Karim, J., \& ud Din, S. (2013). Workplace incivility and counterproductive work behavior. Moderating role of emotional intelligence. Pakistan Journal of Psychological Research, 28, 317-334.

Book, A., Visser, B. A., Blais, J., Hosker-Field, A., Methot-Jones, T., Gauthier, N. Y., Volk, A., Holden, R. R., \& D'Agata, M. T. (2016). Unpacking more "evil": What is at the core of the dark tetrad? Personality and Individual Differences, 90, 269-272. https://doi.org/10.1016/j.paid.2015.11.009

Brunetto, Y., Teo, S. T., Shacklock, K., \& Farr-Wharton, R. (2012). Emotional intelligence, job satisfaction, well-being and engagement: Explaining organisational commitment and turnover intentions in policing. Human Resource Management Journal, 22, 428-441. https://doi.org/10.1111/j.17488583.2012.00198.x

Chen, H., Richard, O., Boncoeur, D., \& Ford, D. (2020). Work engagement, emotional exhaustion, and counterproductive work behavior. Journal of Business Research, 114, 30-41. https://doi.org/10.1016/ j.jbusres.2020.03.025

Christie, R., \& Geis, F. L. (1970). Studies in Machiavellianism. Academic Press.

Cleckley, H. (1941). The mask of sanity: an attempt to reinterpret the so-called psychopathic personality. Mosby.

Cohen, A. (2007). Commitment before and after: an evaluation and reconceptualization of organizational commitment. Human Resource Management Review, 17, 336-354. https://doi.org/10.1016/ j.hrmr.2007.05.001

Czarna, A. Z., Jonason, P. K., Dufner, M., \& Kossowska, M. (2016). The Dirty Dozen Scale: Validation of a Polish version and extension of the nomological net. Frontiers in Psychology, 7, 445. https://doi. org/10.3389/fpsyg.2016.00445

Demerouti, E., Bakker, A. B., Nachreiner, F., \& Schaufeli, W. B. (2001). The job demands-resources model of burnout. Journal of Applied Psychology, 86, 499512. https://doi.org/10.1037/0021-9010.86.3.499

Den Hartog, D. N., \& Belschak, F. D. (2012). Work engagement and Machiavellianism in the ethical leadership process. Journal of Business Ethics, 107, 35-47. https://doi.org/10.1007/s10551-012-1296-4

Derbis, R. (2017). Dualizm zaangażowania w pracę i przywiązanie a jakość życia [Relation between dualism of job engagement, attachment and quality of life] In B. Bartosz, E. Dryll, \& J. Klebaniuk (Eds.), Jakość życia w refleksji psychologicznej [Qualty of life in psychological reflection] (pp. 233-251). Eneteia.

Derbis, R., \& Wirga, T. (2017). Znaczenie doświadczanych emocji dla rozwiązywania zadań problemowych przez makiawelistów [The significance of experienced emotions for solving problem tasks by machiavellians]. Czasopismo Psychologiczne, 2, 383-393.

Elliot, A. J., \& Church, M. A. (1997). A hierarchical model of approach and avoidance achievement motivation. Journal of Personality and Social Psychology, 72, 218-232. https://doi.org/10.1037/00223514.72.1.218

Elliot, A. J., \& McGregor, H. A. (2001). A $2 \times 2$ achievement goal framework. Journal of Personality and Social Psychology, 80, 501-519. https://doi. org/10.1037/0022-3514.80.3.501

Elliot, A. J., \& Murayama, K. (2008). On the measurement of achievement goals: Critique, illustration and application. Journal of Educational Psychology, 100, 613-628. https://doi.org/10.1037/0022-0663. 100.3.613

Fernández-del-Río, E., Ramos-Villagrasa, P. J., \& Barrada, J. R. (2020). Bad guys perform better? The incremental predictive validity of the Dark Tetrad over Big Five and Honesty-Humility. Personality and Individual Differences, 154, 109700. https://doi. org/10.1016/j.paid.2019.109700

Folger, R., \& Skarlicki, D. P. (1998) A popcorn metaphor for employee aggression. In R. W. Griffin, A. O'Leary-Kelly, \& J. M. Collins (Eds.), Dysfunctional behavior in organizations: Violent and deviant behavior (pp. 43-81). JAI Press.

Freud, S. (1914/2004). On narcissism. In J. Rivkin \& M. Ryan (Eds.), Literary theory: an anthology (pp. 67-102). Blackwell Publishing Ltd.

Giacalone, R. A., \& Greenberg, J. (1997). Antisocial behavior in organizations. Sage.

Golembiewski, R., \& Munzenrider, R. (1991). Phases of burnout: Developments in concepts and applications. Praeger.

Gurtman, M. B. (1992). Trust, distrust, and interpersonal problems: a circumplex analysis. Journal of Personality and Social Psychology, 62, 989-1002. https://doi.org/10.1037/0022-3514.62.6.989

Hayes, A. F. (2009). Beyond Baron and Kenny: Statistical mediation analysis in the new millennium. Communication Monographs, 76, 408-420. https:// doi.org/10.1080/03637750903310360

Hodson, G., Book, A., Visser, B. A., Volk, A. A., Ashton, M. C., \& Lee, K. (2018). Is the Dark Triad com-
The association between motivation and counterproductive work behavior 
mon factor distinct from low Honesty-Humility? Journal of Research in Personality, 73, 123-129. https://doi.org/10.1016/j.jrp.2017.11.012

Hollinger, R. C., \& Clark, J. P. (1983). Theft by employees. Lexington Books.

Jakobwitz, S., \& Egan, V. (2006). The dark triad and normal personality traits. Personality and Individual Differences, 40, 331-339. https://doi.org/10.1016/ j.paid.2005.07.006

Jonason, P. K., \& McCain, J. (2012). Using the HEXACO model to test the validity of the Dirty Dozen measure of the Dark Triad. Personality and Individual Differences, 5, 935-938. https://doi.org/10.1016/ j.paid.2012.07.010

Jonason, P. K., Slomski, S., \& Partyka, J. (2012). The Dark Triad at work: How toxic employees get their way. Personality and Individual Differences, 52, 449-453. https://doi.org/10.1016/j.paid.2011.11.008

Jonason, P. K., \& Webster, G. D. (2010). The dirty dozen: a concise measure of the dark triad. Psychological Assessment, 22, 420-432. https://doi. org/10.1037/a0019265

Judge, T. A. (2009). Core self-evaluations and work success. Current Dlirections in Psychological Science, 18, 58-62. https://doi.org/10.1111/j.1467-8721. 2009.01606.x

Judge, T. A., Bono, J. E., Erez, A., \& Locke, E. A. (2005). Core self-evaluations and job and life satisfaction: The role of self-concordance and goal attainment. Journal of Applied Psychology, 90, 257-268. https:// doi.org/10.1037/0021-9010.90.2.257

Judge, T. A., Locke, E. A., \& Durham, C. C. (1997). The dispositional causes of job satisfaction: a core evaluations approach. Research in Organizational Behavior, 19, 151-188.

Kahn, W. A. (1990). Psychological conditions of personal engagement and disengagement at work. Academy of Management Journal, 33, 692-794. https://doi.org/10.2307/256287

Leon, M., Halbesleben, J., \& Paustian-Underdahl, S. (2015). A dialectical perspective on burnout and engagement. Burnout Research, 2, 87-96. https:// doi.org/10.1016/j.burn.2015.06.002

Lipowska, J. (2016). Wypalenie zawodowe a motywacja do pracy i czynniki ja wzmacniajace u kadry pedagogicznej instytucji opiekuńczo-wychowawczych [Job burnout and motivation to work and factors reinforcing it in the teaching staff of educational and care institutions]. Doctoral thesis, Adam Mickiewicz University, Poznań.

Machiavelli, N. (2005). Książę [The Prince]. Zielona Sowa.

Maslach, C., \& Jackson, S. E. (1981). The measurement of experienced burnout. Journal of Occupational Behavior, 2, 99-113. https://doi.org/10.1002/ job.4030020205

Maslach, C., \& Leiter, M. P. (2008). Early predictors of job burnout and engagement. Journal of Applied Psy- chology, 93, 498-512. https://doi.org/10.1037/00219010.93.3.498

Maslach, C., Schaufeli, W. B., \& Leiter, M. P. (2001). Job burnout. Annual Review Psychology, 52, 397-422. https://doi.org/10.1146/annurev.psych.52.1.397

McClelland, D. C., Atkinson, J. W., Clark, R. A., \& Lowell, E. L. (1953). The achievement motive. AppletonCentury-Crofts.

Muris, P., Merckelbach, H., Otgaar, H., \& Meijer, E. (2017). The malevolent side of human nature: a meta-analysis and critical review of the literature on the dark triad (narcissism, Machiavellianism, and psychopathy). Perspectives on Psychological Science, 12, 183-204. https://doi.org/10.1177/17456916 16666070

Murray, H. A. (1938). The Thematic Apperception Test. Manual. Western Psychological Services.

Neuman, J. H., \& Baron, R. (1998). Workplace violence and workplace aggression: Evidence concerning specific forms, potential causes, and preferred targets. Journal of Management, 24, 391-419. https:// doi.org/10.1016/S0149-2063(99)80066-X

Nicholls, J. (1984). Conceptions of ability and achievement motivation. In R. Ames, \& C. Ames (Eds.), Research on motivation in education: Student motivation (Vol. 1, pp. 39-73). Academic Press.

O’Boyle, E. H., Forsyth, D. R., Banks, G. C., \& McDaniel, M. A. (2012). A meta-analysis of the Dark Triad and work behavior: A social exchange perspective. Journal of Applied Psychology, 97, 557579. https://doi.org/10.1037/a0025679.

Paulhus, D. L., \& Williams, K. M. (2002). The Dark Triad of personality: Narcissism, Machiavellianism, and psychopathy. Journal of Research in Personality, 36, 556-563. https://doi.org/10.1016/S00926566(02)00505-6

Penney, L. M., \& Spector, P. E. (2002). Narcissism and counterproductive work behavior: Do bigger egos mean bigger problems? International Journal of Selection and Assessment, 10, 126-134. https://doi. org/10.1111/1468-2389.00199

Poortvliet, M. P., Janssen, O., Van Yperen, N. W., \& Van de Vliert, E. (2007). Achievement goals and interpersonal behavior: How mastery and performance goals shape information exchange. Personality and Social Psychology Bulletin, 33, 1435-1447. https://doi.org/10.1177/0146167207305536

Raskin, R. N., \& Hall, C. S. (1979). A narcissistic personality inventory. Psychological Reports, 45, 590. https://doi.org/10.2466/pr0.1979.45.2.590

Robinson, S. L., \& Bennett, R. J. (1995). A typology of deviant workplace behaviors: a multidimensional scaling study. Academy of Management Journal, 38, 555-572. https://doi.org/10.2307/256693

Schaufeli, W. B., \& Bakker, A. B. (2003). Test manual for the Utrecht Work Engagement Scale. Unpublished manuscript, Utrecht University, Utrecht. Retrieved from http://www.schaufeli.com 
Schaufeli, W. B., \& Salanova, M. (2007). Work engagement: an emerging psychological concept and its implications for organizations. In S. W. Gilliland, D. D. Steiner, \& D. P. Skarlicki (Eds.), Managing social and ethical issues in organizations (pp. 135177). Information Age Publishers.

Schaufeli, W. B., Salanova, M., Gonzalez-Roma, V., \& Bakker, A. B. (2002). The measurement of engagement and burnout: a two sample confirmatory factor analytic approach. Journal of Happiness Studies, 3, 71-92. https://doi.org/10.1023/A:1015630930326

Scherer, K. T., Baysinger, M., Zolynsky, D., \& LeBreton, J. M. (2013). Predicting counterproductive work behaviors with sub-clinical psychopathy: Beyond the Five Factor Model of personality. Personality and Individual Differences, 55, 300-305. https://doi. org/10.1016/j.paid.2013.03.007

Skarlicki, D. P., \& Folger, R. (1997). Retaliation in the workplace: The roles of distributive, procedural, and interactional justice. Journal of Applied Psychology, 82, 434-443. https://doi.org/10.1037/00219010.82.3.434

Spector, P. E., \& Fox, S. (2005). Counterproductive work behavior: Investigations of actors and targets. APA Publishing.

Spector, P. E., Fox, S., Penney, L. M., Bruursema, K., Goh, A., \& Kessler, S. (2006). The dimensionality of counterproductivity: Are all counterproductive behaviors created equal? Journal of Vocational Behavior, 68, 446-460. https://doi.org/10.1016/ j.jvb.2005.10.005

Szabowska-Walaszczyk, A., Zawadzka, A., \& Wojtaś, M. (2011). Zaangażowanie w pracę i jego korelaty: adaptacja skali UWES autorstwa Schaufeliego i Bakkera [Work engagement and its correlates: Adaptation of the UWES scale by Schaufeli and Bakker]. Psychologia Jakości Życia, 10, 57-74.

Zettler, I., Friedrich, N., \& Hilbig, B. E. (2011). Dissecting work commitment: The role of Machiavellianism. Career Development International, 16, 20-35. https://doi.org/10.1108/13620431111107793 